The top of the vessel, for convenience, should be about on a level with the top of the cylinder. When the vessel is opened all of the fumes which come out are sucked down into the down-draft pipe.

With an air pressure of 25 pounds, the suction in the down-draft tube is $2 \frac{1}{4}$ inches of water pressure, and the velocity of the air going through the six-inch cylinder was found by careful anemometer measurement to be 135 feet per minute, which gives a velocity of about I 200 feet per minute in the two-inch down-draft pipe.

FCRMAN HaLl, Vanderbilt UNIVERSITy, NashVille, TENNESSEB.

\title{
PURITY AND VOLATILITY OF PRECIPITATED ANTIMONY SULPHIDE.
}

By LEWIS A. Yootz.

Received April 10, 1908.

This work was taken up to discover whether pure antimony trisulphide could be obtained by precipitation by hydrogen sulphide. The volatility of the product of precipitation when heated in an inert atmosphere came in more or less incidentally in the course of the work as a check on the purity of the sulphide. Practically the only impurity considered however was the chloride.

Most of the work on the determination of antimony by precipitation as sulphide, as is too often the case in analytical work in general, is empirical. The investigator will fall upon a method that approximates accurate results; then by shifting the conditions here or there he finally arrives at a set of conditions that will give results within the limits of experimental error. He then announces his method as an accurate one though often it is accurate merely because of a series of compensating errors.

It might be said in anticipation that such was found to be the case in the method of determining antimony by precipitation as sulphide in the presence of hydrochloric acid, heating the dried sulphide in an atmosphere of carbon dioxide, and weighing.

\section{Purity.}

(I) As a preliminary experiment in the investigation of the purity of the precipitated sulphide, two samples of antimony trichloride of approximately I. 5 grams each were dissolved in $250 \mathrm{cc}$. of water and $30 \mathrm{cc}$. of concentrated hydrochloric acid, the antimony precipitated as completely as possible by hydrogen sulphide gas, the volume of the liquid then increased to 500 or $600 \mathrm{cc}$., warmed nearly to boiling, and saturated with the gas. The sulphides were washed with water saturated with hydrogen sulphide till Io cc. of wash water gave no test for chloride, or but a faint trace. It should be noted that it is very difficult to wash the precipitated sulphide free from chloride, from 1000 to $\mathrm{I} 500 \mathrm{cc}$. of water being required in this and 
in subsequent cases where precipitation was made in the presence of hydrochloric acid. These precipitates were tested qualitatively, and notable quantities of chloride were found in each.

The method of testing for chloride in this case as in all subsequent cases was to fuse the sulphide in sodium carbonate in a porcelain crucible, acidify the fusion with sulphuric acid after taking up with water, filter out the sulphide produced by the acidification and test the filtrate for chloride after the removal of any hydrogen sulphide in the solution. Blanks were run in every case, as sodium carbonate absolutely free from chlorides was found extremely difficult to obtain or to make. Testing for chlorides by making a solution of the trisulphide by means of concentrated sulphuric or nitric acids, was not thought wise, owing to the liability of volatilization of the chloride by the acid, and also owing to the interference in precipitation of chloride by silver nitrate in the presence of antimony. A crucible was tested for chloride by fusion of sodium carbonate in it. No chloride was found. The glaze did not contain chloride.

(2) Thinking that taking a smaller amount of antimony chloride to start with, so as to give less of the sulphide to wash, might effect the amount of chloride in the end, 0.2215 gram of metallic antimony was dissolved in aqua regia, the solution boiled with excess of hydrochloric acid till the nitric acid was decomposed, ending with about $50 \mathrm{cc}$. of 20 per cent. hydrochloric acid. This was then diluted with about $400 \mathrm{cc}$. of water and the antimonic acid treated with hydrogen sulphide till complete precipitation of antimony pentasulphide. The precipitate was then washed till no further test for chloride was found in the filtrate. A sample of the precipitate showed abundant chloride present.

(3) 0.2400 gram of metallic antimony treated as the preceding, but the precipitate dried to constant weight at $\mathrm{I}^{\circ} \mathrm{O}^{\circ}$, was heated for 0.5 hour to $240-250^{\circ}$ in an atmosphere of carbon dioxide. 'This precipitate, assuming it to be antimony trisulphide calculated over to antimony, indicated 0.2397 gram antimony. It will be noted that the sample of sulphide was heated to $250^{\circ}$ in an atmosphere of carbon dioxide, and the results showed only 0 . I 2 per cent. error, yet on testing a strong test for chloride was indicated. The antimony was oxidized to the pentad form and precipitated as pentasulphide, with the thought that the sulphur freed from this sulphide, when transformed to the black modification and triad antimony sulphide, might act to transform any chloride of antimony to the sulphide at the higher temperature.

(4) A sample of 0.325 I gram of antimony sulphide precipitated from a hydrochloric acid solution as usual and dried at I $10^{\circ}$ to constant weight gave 0.3 per cent. chlorine equivalent to 1.45 per cent. SbOCl, supposing the chloride to be in this form under the conditions.

(5) To try the effect of tartaric acid on reducing the amount of adherent 
chloride, a sample of antimony sulphide was prepared from metallic antimony as in the previous cases but 5 grams of tartaric acid were added before precipitation. The precipitate was washed as usual and dried at I IO $^{\circ}$. 0.2954 gram of this sulphide gave, on testing, 0.51 per cent. chlorine equivalent to 2.47 per cent. SbOCl. Another portion of this heated 0.5 hour at $240^{\circ}$ gave 0.242 per cent. chlorine, which, if considered as $\mathrm{Sb}_{4} \mathrm{O}_{5} \mathrm{Cl}_{2}$ as is the case when pure antimony oxychloride is heated to $250^{\circ}$, is equivalent to I . 80 per cent. $\mathrm{Sb}_{4} \mathrm{O}_{5} \mathrm{Cl}_{2}$. 247 grams of $\mathrm{SbOCl}$ by loss of $\mathrm{SbCl}_{3}$ to become $\mathrm{Sb}_{4} \mathrm{O}_{5} \mathrm{Cl}_{2}$ by calculation give $\mathrm{I}_{4}$ grams of $\mathrm{Sb}_{4} \mathrm{O}_{5} \mathrm{Cl}_{2}$, which points strongly to the impurity being $\mathrm{Sb}_{4} \mathrm{O}_{5} \mathrm{Cl}_{2}$ after being heated to $250^{\circ}$. Plainly here the tartaric acid did not reduce the amount of chloride as impurity.

(6) Another sample treated as in the preceding case, but with the tartaric acid omitted, gave chlorine 0.66 per cent. on the sulphide dried at I $10^{\circ}$, but 0.45 per cent. after being heated to $240^{\circ}$ for 0.5 hour.

(7) A sample from 0.2680 gram of antimony dissolved as usual in aqua regia, precipitated by hydrogen sulphide, washed as usual, precipitate dissolved in ammonium sulphide, reprecipitated by acetic acid, dried at $110^{\circ}$, heated in intervals of 0.5 to $\mathrm{I} .5$ hours in carbon dioxide for a total of nine hours, showed 0 . 1o per cent. chlorine yet present which is equivalent to 0.9 per cent. $\mathrm{Sb}_{4} \mathrm{O}_{5} \mathrm{Cl}_{2}$.

These samples of results represent only a few of a much larger number of experiments carried out with varying amounts of antimony and hydrochloric acid present. In no case was it found possible to produce a precipitate of antimony sulphide, either the trisulphide or the pentasulphide, even approximately free from chloride, nor was it possible to remove the chloride by washing, though a point could be reached after long washing where the wash water contained but the merest trace of chloride. Yet these samples contained as high as 2.47 per cent. of chloride calculated as $\mathrm{SbOCl}$, and in one case after heating for 0.5 hour in a carbon dioxide stream to $250^{\circ}$, showed 4.05 per cent. calculated as $\mathrm{Sb}_{4} \mathrm{O}_{5} \mathrm{Cl}_{2}$.

The tartaric acid was without apparent effect in reducing the amount of chloride retained by the precipitate. Further, it was surprising that after dissolving the precipitated sulphide in ammonium sulphide free from chloride, and reprecipitating by acetic acid also free from chloride, the sulphide yet contained chloride, and after heating for 9 hours to 250 degrees there was still present 0 . Io per cent. chlorine.

\section{Volatility of the Precipitated Sulphide.}

A large number of tests of the volatility of these sulphide precipitates were carried out under varying conditions of precipitation. Uniformly the precipitates were heated in an atmosphere of carbon dioxide at a temperature of approximately $25^{\circ}$ after drying to constant weight at usually IO5-I $10^{\circ}$ in air.

The precipitated sulphides were collected and washed in a Gooch cruci- 
ble with asbestos filter. After drying the precipitates in the crucible, they were in each case placed in a small beaker covered with a watch glass perforated to admit a thermometer and carbon dioxide delivery tube. The beaker and crucible so arranged were then heated in an asbestos oven after the removal of the air from the beaker by carbon dioxide.

A few only of the tests will be given as illustrations:

(I) 1.5 grams of antimony chloride were dissolved in water and enough hydrochloric acid added to give a clear solution, the antimony precipitated by hydrogen sulphide, filtered, washed till the wash water was free from chloride and dried in air at $110^{\circ}$. This sample was heated at varying intervals of from $I$ to 5 hours in an atmosphere of carbon dioxide at a temperature of $250^{\circ}$, altogether for 34 hours. The loss on approximately I gram of the precipitate averaged I.I mg. per hour though the loss per hour was somewhat irregular. The last hour it lost $2.5 \mathrm{mg}$.

(2) A sample of 0.1931 gram metallic antimony was dissolved in aqua regia, excess of nitric acid decomposed by boiling with hydrochloric acid, diluted and precipitated as usual. After heating for I hour at $230^{\circ}$ the sulphide calculated over to antimony indicated 0.1936 gram antimony; results were thus quantitative so far. After heating for 1.5 hours more the weight was reduced by $5.8 \mathrm{mg}$, or something over 2 per cent. loss.

(3) To test the volatility of the sulphide free from chloride a gram of tartar emetic purified by crystallization was dissolved in water and precipitated after acidification with a small amount of sulphuric acid and a larger amount of acetic acid. The precipitate after drying at $110^{\circ}$ weighed 0.4942 gram. After heating for 3 hours at $250^{\circ}$ it weighed 0.4938 . Loss $0.4 \mathrm{mg}$. Thus the sulphide free from chioride is practically non-rolatile.

(4) Another sample of 0.1810 gram of antimony was dissolved and precipitated as usual. The sulphide was then dissolved by ammonium polysulphide and reprecipitated with dilute sulphuric acid. This was repeated three times. Finally the precipitate was washed, thoroughly dried and heated to $250^{\circ}$ as usual. After the first large loss due to the sulphur from the pentasulphide, 2.5 hours' heating in three intervals caused a loss of $1.7,2.6,2.7 \mathrm{mg}$. successively:

As was shown by a quantitative test for chloride in another sample similarly treated, the remarkable thing here is the persistency with which the chloride is retained by the precipitated antimony chloride, for it is the presence of chloride that causes the volatility.

These illustrations are ample to show the impossibility of getting constant weight at $250^{\circ}$ with chloride present.

Is the method accurate? It is almost useless to discuss this question for the method of precipitating antimony as sulphide, either trisulphide or pentasulphide, transforming to the black modification, and volatiliza- 
tion of the excess of sulphur in an atmosphere of carbon dioxide at $250^{\circ}$ has long been used with good results for accuracy in the hands of many analytical chemists.

But merely to bring the fact freshly to our minds again, I give here a dozen or more determinations made by starting, with metallic antimony, with the temperature, time of heating in carbon dioxide atmosphere, and the acid used.

\begin{tabular}{|c|c|c|c|c|c|c|c|}
\hline $\begin{array}{c}\text { Wt. of Sb. } \\
\text { O. I } 931\end{array}$ & \multicolumn{4}{|c|}{ HCI acid } & $\begin{array}{r}\text { Temp. } \\
227^{\circ}\end{array}$ & $\begin{array}{c}\text { Time, hrs. } \\
0.5\end{array}$ & $\begin{array}{c}\text { Sb found. } \\
0.1936\end{array}$ \\
\hline 0.2040 & ; & $\therefore 6$ & & & $245^{\circ}$ & 0.5 & 0.2037 \\
\hline 0.2287 & is & 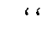 & & & $240^{\circ}$ & 0.5 & 0.2283 \\
\hline 0.3685 & 66 & 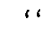 & & & $250^{\circ}$ & 0.5 & 0.3692 \\
\hline $0 . I_{4} 4$ & " & " & & & $245^{\circ}$ & 0.5 & $0.14 I 5$ \\
\hline 0.2400 & " & is & & & $240^{\circ}$ & 0.5 & 0.2397 \\
\hline 0.2586 & $\mathrm{HCl}$ & and & Tar. & $\operatorname{acid}$ & $240^{\circ}$ & 0.5 & 0.2584 \\
\hline 0.2405 & as & ، & $\because$ & $\because$ & $240^{\circ}$ & o. 5 & 0.2409 \\
\hline 0.2035 & $\because$ & 6 & ، & 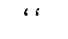 & $250^{\circ}$ & 0.5 & 0.2031 \\
\hline 0.2060 & $\therefore$ & ‘ & “ & ‘ & $245^{\circ}$ & 0.5 & 0.2066 \\
\hline o. I 592 & " & $\because$ & $\because$ & $" \hookrightarrow$ & $250^{\circ}$ & 0.5 & 0.1596 \\
\hline 0.2214 & “ & “ & $"$ & $" ،$ & $240^{\circ}$ & 0.5 & $0.222 \mathrm{I}$ \\
\hline
\end{tabular}

This is sufficient to show that quantitative results may be obtained. In no case is the error over 0.3 per cent. and ustually from 0. I to 0.2 per cent. even when calculated to metallic antimony, which is clearly close enough for any ordinary analytical work. To be sure, if the samples were to be heated much longer than 0.5 hour the error would rapidly increase and soon would become large owing to the volatility of the chloride.

It is not surprising that the results should be quantitative when the sulphide is heated only for a short time just long enough to volatilize the sulphur either free or combined as pentasulphide and to transform the sulphide to the black modification, for the equivalent molecular weights for $\mathrm{Sb}_{2} \mathrm{~S}_{3}$ - $\mathrm{SbOCl}$ and $\mathrm{Sb}_{4} \mathrm{O}_{5} \mathrm{Cl}_{2}$ are $168.2, \mathrm{I}_{7} 1.45$ and 157.9 respectively and thus not very widely apart, so that as far as the weight of the precipitate is concerned even several per cent. of $\mathrm{SbOCl}$ or even $\mathrm{Sb}_{4} \mathrm{O}_{5} \mathrm{Cl}_{2}$ as an impurity would give a weight practically the same as though the antimony were all in the form of sulphide.

I am greatly indebted to Mr. Alva G. Austin for carrying out much of the detail of this work.

CHEMTCAL LABORATORIES, LAWRENCE UNIVBRSITY,

APPLETON, WIS.

\section{A SCHEME FOR THE SEPARATION OF THE RARE EARTHS.}

\section{JAMES.}

Received April 2, 1908.

In this communication, a comparatively simple scheme for the separation of mixtures of the rare earths is offered in the hope that it may prove of 